MISTRAL MISTRAL

Journal of Latin American Women's

Intellectual \& Cultural History

\title{
La política queer es cosa de niñes: Imaginarios infantiles, afectos ingenuos y repertorios visuales de la protesta sexual contemporánea en Argentina
}

\author{
Nicolás Cuello, Universidad de Buenos Aires / CONICET, Argentina
}

To cite this article: Nicolás Cuello. 2021. "La política queer es cosa de niñes. Imaginarios infantiles, afectos ingenuos y repertorios visuales de la protesta sexual contemporánea en Argentina." Mistral: Journal of Latin American Women's Intellectual \& Cultural History 1 (2): 65-83, https://doi.org/10.21827/mistral.2.38029

\begin{abstract}
This article explores the ways in which a series of artistic activism groups in the recent history of social protest in Argentina, including Mujeres Públicas, Fugitivas del Desierto and Serigrafistas Queer, linked to the feminist, lesbian and sex-dissident movements, occupied public space and social mobilizations through a set of visual devices and performative actions that can be thought of as forms of queer appropriation of childish imaginaries. Appealing to the critical resemantization of the hetero-reproductive economies inscribed both in the bodily choreographies of popular games and in the material life of the toys they used, these groups mobilized public images through naive affects such as cuteness, tenderness and joy to make visible, interrupt, and also divert the productive scripts of modern sex-politics and instituted notions of politics.
\end{abstract}

\section{Keywords}

Emotions; Childish Imaginaries; Art History; Artistic Activism; Sexual Politics

\section{Resumen}

Este artículo explora los modos en que una serie de grupos de activismo artístico en la historia reciente de la protesta en Argentina, entre ellos Mujeres Públicas, Fugitivas del Desierto y Serigrafistas Queer, vinculados a los movimientos feministas, lésbicos y sexodisidentes, ocuparon el espacio público, y las movilizaciones sociales, a través de un conjunto de dispositivos visuales y acciones performáticas que pueden pensarse como formas de apropiación queer de los imaginarios infantiles. Apelando, entonces, a la resemantización crítica de las economías heteroreproductivas inscritas tanto en las coreografías corporales de los juegos populares como en la vida material de los juguetes que utilizaron, movilizaron imágenes públicas a través de afectos ingenuos como lo lindo, la ternura y la alegría para visibilizar, interrumpir y desviar los guiones productivos de la sexopolítica moderna y las nociones instituidas del acontecimiento político.

\section{Palabras clave}

Emociones; Imaginarios Infantiles; Historia del Arte; Activismos Artísticos; Políticas sexuales 


\title{
La política queer es cosa de niñes. Imaginarios infantiles, afectos ingenuos y repertorios visuales de la protesta sexual contemporánea en Argentina
}

\author{
Nicolás Cuello, Universidad de Buenos Aires / CONICET, Argentina
}

\section{Niñes queer, $; A$ desorganizar!}

Los repertorios visuales que acompañan la emergencia de nuevos protagonismos sociales en la historia reciente de la política argentina se han caracterizado por el uso crítico de saberes especializados del arte contemporáneo con el deseo de incidir de alguna forma en el territorio de lo político. Es por eso que, especialmente desde el retorno de la democracia, podemos observar la emergencia de una matriz diferencial de agencia política que se vuelve posible gracias a la experimentación sensible con otros lenguajes expresivos de lo común, en donde se redefine la experiencia de la organización social, el espacio público y el lugar que el cuerpo ocupa en dichas formas de antagonismo crítico.

Si bien el conjunto de iniciativas populares que articularon este nuevo fenómeno cultural de aparición de lo político pueden ser diagramadas genealógicamente a partir de las similitudes que presentan en sus modos de hacer, me interesa detenerme en el aporte específico realizado por grupos de activismo artístico feministas, lésbicos y queer como Mujeres Públicas (2003), Fugitivas del Desierto (2004) y Serigrafistas Queer (2007), en tanto elaboraron una serie de herramientas diferencialmente innovadoras, a partir de la recuperación de objetos centrales en el desarrollo de las infancias: los juegos y los juguetes, desde los cuales materializaron, en el marco de la protesta social, señalamientos críticos sobre los regímenes de producción sexogenérica de los cuerpos. Me interesa pensar, entonces, un conjunto particular de sus acciones como formas de apropiación queer de los imaginarios infantiles que, apelando a la resemantización crítica de las economías hetero-reproductivas, inscritas tanto en las coreografías corporales de los juegos populares como en la vida material de los juguetes que utilizaron como dispositivos visuales y/o performáticos para ocupar el espacio público, movilizaron imágenes públicas a través de afectos ingenuos como la ternura, la inocencia y la alegría para visibilizar, interrumpir y desviar los guiones productivos de la sexopolítica moderna.

En este sentido, a partir del análisis de estas experiencias, este trabajo se propone pensar en las resonancias que dichos cruces entre prácticas artísticas y políticas sexuales introducen a los regímenes de control afectivo de aquello que he denominado straight-politik: un régimen prescriptivo de inteligibilidad de lo político que centra su poder en la jerarquización desigual de aquellas formas de transformación de lo real que responden a principios eficaces como la coherencia metodológica, la rectitud de sus objetivos, la épica melodramática, la representación afirmativa del deseo, y, en este caso en particular, observaremos también, la seriedad enunciativa y la madurez del sentido en sus repertorios visuales. Ante dichos límites, me interesa pensar la potencial fuerza desestabilizadora que introducen las apropiaciones torcidas de lo infantil en estos lenguajes expresivos de la protesta sexual, en tanto prometen desafiar no sólo la subestimación sistemática de aquellas formas de imaginación corridas de la exigencia heterocentrada del adultocentrismo, sino también reconfigurar las limitaciones que este aparato de captura supone para el acontecimiento de la transformación social. 


\section{Activismo artístico menor}

El ciclo de movilizaciones que inaugura la profundización de la crisis neoliberal en Argentina durante el curso de la década de los noventa y principios de los 2000 vio emerger una serie innovadora de lenguajes expresivos en el corazón de los nuevos movimientos sociales que protagonizaron la resistencia ante dicha crisis laboral de extrema agudeza, producto principalmente del desguace económico que había provocado la oscura combinación entre la especulación privada, el colapso bancario y una gobernabilidad intoxicada por intereses financieros escritos sobre la voluntad de un pueblo distraído por la promesa cruel de los consumos globales. En el transcurso temporal de este derrumbe socioeconómico, ahora intensificado por la pérdida total de legitimidad institucional de la clase política, aquellos movimientos que tomaron las calles para materializar formas de alianza antagonista ante los múltiples efectos de precarización de sus vidas, formaron plataformas horizontales de invención, socialización y multiplicación de recursos creativos para intervenir en estos escenarios de disputa, potenciando así los vínculos entre múltiples facciones del cuerpo social que lograron crear a partir de una imaginación coordinada, un principio de articulación política de las diferencias en torno a la defensa de la vida (Lazzarato 2006).

En este escenario se concentra una parte de la historia de aquellos grupos conformados por artistas visuales, cineastas, periodistas y activistas sociales que, para Ana Longoni (2005; 2009), promovieron acciones, tanto en el espacio público como en las instituciones artísticas, que voluntariamente buscaron proporcionar identidad y visibilidad a los conflictos en curso, contribuyendo a la creación de otros modos de hacer de la protesta social que recuperaron recursos artísticos con la voluntad de tomar posición e incidir de alguna forma en el territorio de lo político. Este conjunto de prácticas caracterizadas por la autora como activismos artísticos, un término que retoma de modo situado la autodefinición propuesta por el dadaísmo alemán, se refiere a aquellos modos de producción de formas estéticas y de relacionalidad que anteponen la acción social a la tradicional exigencia de autonomía del arte, y sobre los cuales ha propuesto un diagrama de coyunturas políticas para su comprensión, que si bien no buscan explicar homogéneamente sus particularidades, sí dan contexto a la operatividad singular de su emergencia (Longoni 2010).

Si bien a partir de dicho término Longoni crea un posible modelo de inteligibilidad histórica para aquellas prácticas que intersectaron cruces entre arte y activismo, desde inicios de la década de los ochenta hasta avanzada la década de los años 2000 (Longoni y Bruzzone 2008, Longoni 2009, 2010; 2012a; 2012b) posibilitando la creación de genealogías (Longoni 2010a, 2010b) y la apertura refractaria de preguntas en constante problematización sobre los vínculos nunca pacíficos entre arte y política en la Argentina reciente, ha sido progresivamente interpelado en sus entendidas limitaciones en tanto concentra la fuerza de su imaginación genealógica a relatos que en su circulación institucional han asimilado, por un lado, "lo nacional" con lo acontecido principalmente en la Ciudad de Buenos Aires, su capital federal, reiterando un conjunto de casos cuya insistencia empieza a somatizar los efectos negativos de todo proceso de canonización, especialmente gracias a la emergencia de "escenas locales" que desafían su estabilidad histórica (Di Filipo 2019, Perez Balbi 2019); y por otro, porque ha logrado normalizar temáticamente los sentidos movilizados por estas prácticas, inhabilitando el reconocimiento de cómo los regímenes productivos del sistema sexo-género (Butler 2007) influyen en la historia de resistencia de aquellos cuerpos que han sido implicados en la ocupación del espacio público. 
Si bien, recientemente, se ha propuesto sumar dos acontecimientos singulares para la historia de los activismos feministas y queer locales, como fueron la sanción de la Ley de Matrimonio Igualitario en el año 2010 y la consecuente sanción de la Ley de Identidad de Género en el año 2012 (Cuello 2014) a las coyunturas objetivada por Ana Longoni como escenarios de proliferación de practicas reconocidas como activismo artístico, ${ }^{1}$ dado que aportaron complejidades indiscutidas en la génesis y en el accionar concreto de grupos feministas, lésbicos y queer, la asociación indiscriminada del activismo artístico con un repertorio de temas vinculados con exclusividad a la violencia política y a la precariedad económica ha producido un régimen de invisibilidad y un estratégico desplazamiento temporal de carácter valorativo sobre este conjunto de prácticas. En las últimas dos décadas, y un poco antes también, estas prácticas se caracterizaron por recuperar recursos artísticos con la voluntad de interferir en el territorio de lo político movilizando sentidos críticos desde repertorios visuales de protesta que incluyeron, a diferencia de otros grupos, temáticas, materialidades, espacios y afectos sistemáticamente subestimados desacreditados en su efectividad política, como por ejemplo, los imaginarios infantiles.

Me interesa así considerar estas formas conflictivas de representación de los activismos artísticos vinculados a la política feminista, lésbica y queer, como parte de una economía compleja de minorización, es decir, un proceso de infantilización feminizante que construye sistemas de reconocimiento, marcos de legitimidad y posibilidades de análisis desiguales, a partir de la demarcación de un tipo de activismo artístico verdaderamente "político", serio, conmovedor, con mayúsculas, es decir, mayor o adulto, comprometido con causas consensuadas tradicionalmente como lo urgente, y por otro lado, un activismo artístico menor, asociado a la inmadurez, a lo postergable, desestimado por la ingravidez de sus repertorios afectivos que en su obsesión narcisista, superficial, con el cuerpo, el placer y la identidad, no alcanzan a afectar las verdaderas estructuras del poder, es decir, acciones meramente culturales (Butler 2016) sin incidencias significativas en el arduo trabajo de la transformación social.

En este sentido, me interesa a continuación recuperar una serie de acciones

\footnotetext{
${ }^{1}$ Ana Longoni identifica al menos tres coyunturas en las que emergierongrupos de activismo artístico. La primera está vinculada al surgimiento de la agrupación HIJOS (Hijos por la Identidad y la Justicia contra el Olvido y el Silencio) en el año 1996, que se constituyó en un espacio de encuentro y acción política de hijos e hijas de personas detenidas-desaparecidas durante la última dictadura militar, cuyas movilizaciones se caracterizaron por la ocupación del espacio público junto a grupos de artistas y activistas culturales como el Grupo de Arte Callejero y Etcétera en la ciudad de Buenos Aires, pero tambien Las Chicas del Chancho y el Corpiño, y Costuras Urbanas en la ciudad de Córdoba, que trabajaron no solo en el proceso colectivo de lo que se denomino "escraches", acciones directas que denunciaban públicamente la impunidad de los represores, sino tambien en el señalamiento crítico del empobrecimiento generalizado durante el gobierno de Carlos Menem. La segunda coyuntura, de inmediata aparición, está vinculada a la eclosión de la crisis neoliberal en el2001, que empujó a una sociedad diezamada economicamente a la urgencia de crear articulaciones colectivas que se tradujeran en una nueva forma de antagonismo. Allí surgieron grupos como Taller Popular de Serigrafía (TPS), Argentina Arte (posteriormente Arde! Arte), Colectivo KononuestraLucha e Intergalaktica, en la ciudad de Buenos Aires. Pero tambien Pobres Diablos, Cateaters y acciones vinculadas al pedido de justicia por Claudo "El Pocho" Leptratti en Rosario (Di Filippo 2019). Por último, la tercera de estas coyunturas señaladas por Longoni, será en torno a la segunda desaparición de Jorge Julio López en la Ciudad de La Plata, un ex detenido desaparecido militante peronista y albañil retirado, testigo clave en los Juicios por la Verdad, especialmente en el juicio contra el represor Miguel Etchecolatz. Ver Longoni 2005, 2009, 2010 y Perez Balbi 2019.
} 
producidas por estos grupos de activismo artístico que se orientaron a la socialización de herramientas estético políticas para una práctica feminista, lésbica y queer de acción directa, proponiendo programas de intensa producción callejera desde los cuales intervenir de manera crítica no sólo en las retóricas heterocentradas de la organización social del espacio público mediante la visibilización rábica de múltiples identificaciones sexuales de carácter no normativo o de torcimientos performáticos a la estabilidad de los géneros, sino también produciendo una crítica incisiva a la normalización afectiva del acontecer de lo político a través de la creación de dispositivos visuales y/o performáticos que se apropiaron de los imaginarios infantiles en dichos contextos de movilización social para activar procesos complejos de singularización subjetiva.

\section{La mancha te toca}

En medio del agitado escenario que marcaba la ya mencionada crisis económica, y junto a las estrategias sociales de organización política que emergieron como respuestas para la recomposición de un cuerpo social azotado por la precariedad, irrumpe de manera incómoda la práctica de Mujeres Públicas. Integrado por Magdalena Pagano, Lorena Bossi, Fernanda Carrizo, junto a Verónica Fulco y Pedro Marin (quienes participaron solo en sus primeros años), se definirán como un "grupo feminista de activismo visual" cuyas principales resonancias críticas derivaron no sólo en la necesaria renovación consciente de los lenguajes sensibles de la política feminista (Rosa 2010), explorando imaginarios visuales, formas de acción performáticas y estrategias comunicativas de libre circulación que desafiaban al igual que otros grupos contemporáneos los vínculos entre arte y política, sino también en el arriesgado abordaje de problemáticas feministas que hasta el momento resultaban incómodas, por el tipo de discusiones y tensiones que ponían en juego.

La recepción conflictiva de su primer acción, el afiche Todo con la misma aguja, en la movilización por el Día Internacional de la Mujer Trabajadora, el 8 de marzo del 2003, por parte de algunas activistas feministas al momento de su colocación, dada la simplicidad de sus formas, la ausencia de firma y la opacidad de su mensaje, podría interpretarse como uno de los síntomas que explica no sólo el contexto ríspido de su surgimiento, sino también las resonancias positivas de su constitución como grupo: la necesidad del feminismo de renovar su propio lenguaje (Rosa 2010). Esta apuesta por abordar problemáticas feministas desde una exploración visual, performática y comunicativa recuperaba esos modos de acción del arte crítico que las había encontrado e interpelado anteriormente en su trayectoria como artistas y activistas: Fernanda Carrizo había formado parte del grupo Costuras Urbanas -surgido en el año 1997 como una deriva de un taller dictado por Juan Carlos Romero y Teresa Volco en la capital de la provincia de Córdoba-, y junto a Lorena Bossi formaban en simultáneo el Grupo de Arte Callejero (GAC). Por su lado, Magdalena Pagano había estado vinculada a círculos de poesía visual, reflexión y producción artística junto a Teresa Volco, Juan Carlos Romero e Hilda Paz, entre otros, quienes tenían una importante trayectoria en agenciar colectivos de producción artística para la intervención en el espacio público mediante afiches políticos y acciones performáticas desde las cuales distribuir objetos múltiples de agitación poética en contextos de movilización social o en espacios específicos del campo artístico argentino. De este modo, Mujeres Públicas se ubica en dichas coordenadas de acción, produciendo, desde una mirada humorística y explícitamente provocadora, enunciados feministas críticos por medio de herramientas visuales de 
intervención política de libre circulación.

En octubre del año 2004, durante el XIX Encuentro Nacional de Mujeres en la provincia de Mendoza, Mujeres Públicas intervino el acto de inauguración, ese momento en el que se reúnen públicamente las distintas comitivas feministas, los movimientos sociales y las activistas independientes a la espera de la apertura oficial, con la acción La mancha lesbiana: una bandera naranja de dieciséis metros desplegada en alto con una consigna decididamente visible en letras negras que rezaba "las lesbianas ya no jugamos a las escondidas, ahora jugamos a la mancha" delimitaba un espacio en el que dos pelotas inflables de gran tamaño con la leyenda "la mancha lesbiana te toca" rebotaban entre las participantes, quienes alegremente se entregaban al juego propuesto de empujarlas en el aire y no dejarlas caer.

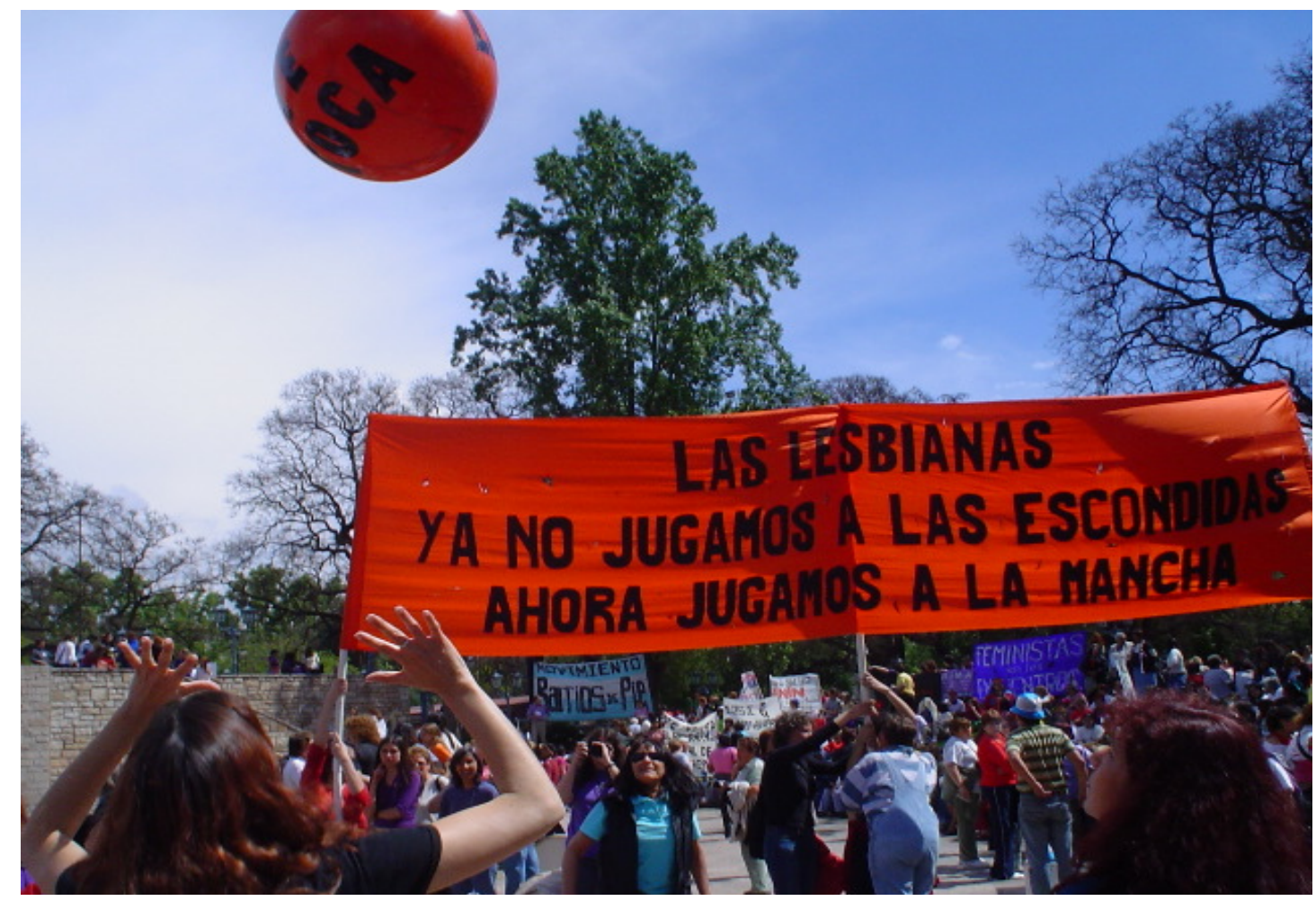

Figura 1. La mancha lesbiana, Mujeres Públicas, 2004. Registro de la intervención en el XIX Encuentro Nacional de Mujeres, Mendoza, Argentina. Colección de las artistas.

Como acción, La mancha lesbiana se proponía visibilizar e evidenciar la identidad y presencia de la política lésbica dentro de los movimientos de mujeres feministas, tradicionalmente compuestos por mujeres heterosexuales. Es que como reconoce la historiadora del arte María Laura Rosa, una parte importante del trabajo de Mujeres Públicas estuvo dedicado a señalar de manera crítica, hacia dentro del feminismo, preguntas que intentaron desnaturalizar el heterocentrismo con el que la voz de este movimiento político se ha construido históricamente (Rosa 2010). Un tipo de accionar que buscaba abrir espacios para reflexionar sobre la identidad lésbica, la invisibilidad institucionalizada, la lesbofobia externa e interiorizada, como también la violencia entre lesbianas. En ese sentido, La mancha lesbiana interseccionó a partir de la movilización de afectos alegres que derivaban de la apropiación de un juego infantil tan popular como la mancha, centrado en las economías de distancia-proximidad entre cuerpos, donde algunos tienen la tarea de escapar de aquel que recibe por contacto corporal directo el mote de "manchado", estableciendo roles efímeros entre cuerpos amenazantes y amenazados, una representación crítica de la lesbofobia estructural de la política 
feminista y los movimientos de mujeres. A través de este juego no solo se escenificaba irónicamente ese peligro latente y aquella potencia que el lesbianismo puede significar para los feminismos que concentran su fuerza transformadora en un sujeto político restringido a las mujeres heterosexuales, sino también un tipo de representación sexual de una identidad política que afirma productivamente una ética a partir de la exageración celebratoria de la diferencia, la promiscuidad del contacto corporal. Lo lésbico no queda restringido a esa identidad preestablecida normativamente por el sentido común como una condición enferma del deseo o una perturbación de la mente, sino como una identificación viral capaz de expandirse placenteramente gracias a otra lógica del contagio, en este caso, alegre, entre cuerpos en juego.

Frente al pánico sexual, pero también sobre otras formas de estigma político que arrastran de manera subyacente presupuestos patologizadores de la diferencia lésbica, el juego y la alegría aparecían como modulaciones expresivas que pulsaban contradictoriamente por abrir espacios para el abordaje incómodo de las violencias que se implican en la subestimación, el silenciamiento, o directamente en la desaparición de las lesbianas como protagonistas históricas y trabajadoras incansables de los movimientos feministas en Argentina. Esta ambivalencia fue posible gracias a la apropiación torcida de este juego popular y el capital afectivo acumulado en las memorias corporales de las asistentes de dicho encuentro, que permitía a través de la reactivación de los recuerdos asociados a la diversión infantil, flexibilizar las resistencias políticas, afectivas y subjetivas que dan continuidad al estigma y la violencia social sobre las lesbianas, en un contexto en donde el sexo, la sexualidad y el género resultaban temas no prioritarios para las agendas de los movimientos sociales. Por efecto de un desplazamiento epistemológico heterosexista, no supieron articular las complejas conexiones entre los efectos decadentes de una crisis político económica tan profunda como la que se había vivido recientemente y los modos desiguales de precarización de los cuerpos corridos de la norma hetero.

Oponiéndose al disimulo de la normalización de la diferencia sexual, esta acción, como uno de los tantos dispositivos visuales y/o performáticos en el trabajo de Mujeres Públicas, hacía uso fluido de los imaginarios infantiles para llamar la atención tanto sobre lo insistente como sobre lo intolerable, torciendo la neutralidad indolente implicada en las formas tradicionales de organización política cuya negación de la alteridad sexual retrasa la urgencia de invertir en la transformación colectiva de las opresiones que recaen sobre los cuerpos lésbicos de manera diferencial. La Mancha Lesbiana produjo así un descalce incontrolable, y casi imperceptible, a la experiencia de la comodidad de los lenguajes tradicionales de la creatividad política feminista, haciendo uso de dispositivos ingenuos, infantiles y lúdicos para delinear socialmente el funcionamiento de las tecnologías reproductivas de la violencia heteropatriarcal (Ngai 2005), pero también para situar estas marcas como resultados de procesos complejos, donde se incluyen las dinámicas de organización de la política emancipatoria.

\section{Figuras de acción}

También a principios del 2004, otro grupo de activistas involucradas en las primeras experiencias de articulación feminista en la provincia de Neuquén, en el sur de Argentina, sintieron la necesidad de producir espacios específicos para la circulación de saberes y experiencias sobre sus vidas como lesbianas. Fue así como conformaron el Grupo de Reflexión Lésbica, donde experimentaban dinámicas grupales de objetivación crítica de la vida personal, junto con lecturas compartidas y debates 
políticos sobre textos escritos por autoras feministas, lesbianas y queer. Este espacio fue una de las primeras agencias políticas locales del sur del país en desarrollar procesos de politización de la visibilidad lésbica que hasta el momento se habían visto obstruidos por los cercos epistemológicos que organizaban los discursos feministas tradicionales, organizados de forma indiscutida e inamovible en torno al sujeto político "mujer" pero también mediado por retóricas discursivas y estrategias de acción que reducían su campo de operatividad a un conjunto de transformaciones en la esfera legal.

Una de las resonancias más importantes de aquella experiencia fue dar lugar a la conformación del grupo de activismo lésbico feminista Fugitivas del Desierto, integrado por val Flores, Macky Corbalán, Bruno Viera y Cristina Martínez. Constituido a partir de una vibrante urgencia por nombrarse, este grupo propuso desde sus comienzos habitar y visibilizar la identidad lesbiana en la calle, de manera crítica y fundamentalmente poética, alejándose de los mecanismos de intervención tradicionales de la política de izquierda y de las dinámicas representativas del feminismo heterosexual, para comenzar un proceso de politización de la vida cotidiana como lesbianas feministas desde el mentado "interior" del país.

Los modos de acción política desde los que se enunció Fugitivas del Desierto, tenían como lenguaje la experimentación con objetos múltiples, que en repetidas oportunidades incluyeron juguetes de plástico de pequeño formato, utilizados popularmente en cumpleaños infantiles, instalaciones gráficas compuestas de afiches, volantes y poemas, intervenciones callejeras realizadas con pegatinas, graffitis y stencils, a los que llamaron en su conjunto "artillería artístico-política", es decir, herramientas de interpelación poética con lenguaje pendenciero, que buscaban en su ocupación desobediente del espacio público, desmantelar la producción de subjetividades heteronormadas abriendo grietas para la representación y la acción de una política lésbica inconforme e inapropiada con los estándares establecidos de la aceptación y la respetabilidad. Estos modos de producir política desde dispositivos visuales y/o performáticos que se servían de materialidades precarias, con un carácter afectivo decididamente provocador, conflictivo, pero al mismo tiempo humorístico, las situó en un lugar disruptivo en el escenario de articulación política local y de la época. En principio porque producían situaciones de experimentación imaginativa radical que ponían en jaque los procesos de normalización de la diversidad sexual en curso y empujaban los imaginarios culturales hegemónicos en torno a las posibilidades sexuales del cuerpo, abriendo en su lugar un flujo inventivo de experiencias vitales y de identificaciones sexuales más libres, sin reproducir de manera ambiciosa la coherencia o la rectitud política que identificaban en los grupos más reconocidos de aquel momento. Entendiendo así al feminismo como una serie de prácticas diversas, dispares, y a menudo, contradictorias, que dibujan, sin delimitarlo nítidamente, un fértil territorio de confrontación y diálogo (Fugitivas del Desierto 2010) y no como un campo de acción política estructurado, orgánico y cerrado en la obtención de derechos para una identidad sexogenérica vulnerada en particular.

Me interesa recuperar aquí una de sus últimas acciones, realizada en el año 2008, que representa uno de los momentos de mayor experimentación lúdica y humorística en su vasta producción. En ella puede identificarse un rasgo constitutivo del tipo de ejercicios políticos que como grupo de activismo artístico llevaron adelante: la producción de experiencias a través de las cuales nombrar, señalar y posiblemente transformar la violencia permanente de las tecnologías de modulación sexopolítica del cuerpo a través de las cuales trabaja la heterosexualidad como régimen político, creando espacios de afectación colectiva mediante la toma del espacio público en las que hacen circular una imaginación político de carácter experimental en torno a las potencias 
singularizantes de lo lésbico.

El afiche AXN lésbica 1.0 - Kit autoinstalable para boicotear el régimen político de la heterosexualidad, fue especialmente realizado para el 1er Encuentro Nacional de Mujeres Lesbianas y Bisexuales organizado durante el 2008 en la ciudad de Rosario, convocado por EspArtiLes, un espacio de articulación de activistas lesbianas de distintas provincias del país fundado en el año 2004, en el mismo momento en que Fugitivas emergía como grupo. Para val flores (2009), integrante fundadora, $A X N$ lésbica fue una producción visual que transformó la caja de herramientas convencional, privativa de la cultura material de profesiones heteromasculinizadas, en un set de lucha de la disidencia sexual, parodiando desde su título el nombre de un reconocido canal de televisión que emitía películas de acción para una audiencia mayoritariamente de varones, AXN.

\section{AXN MBSTBICA}

KIT AUTOINSTALABLE PARA BOICOTEAR EL RÉCIMEN POLÍTICO DE LA HETEROSEXUALIDAD

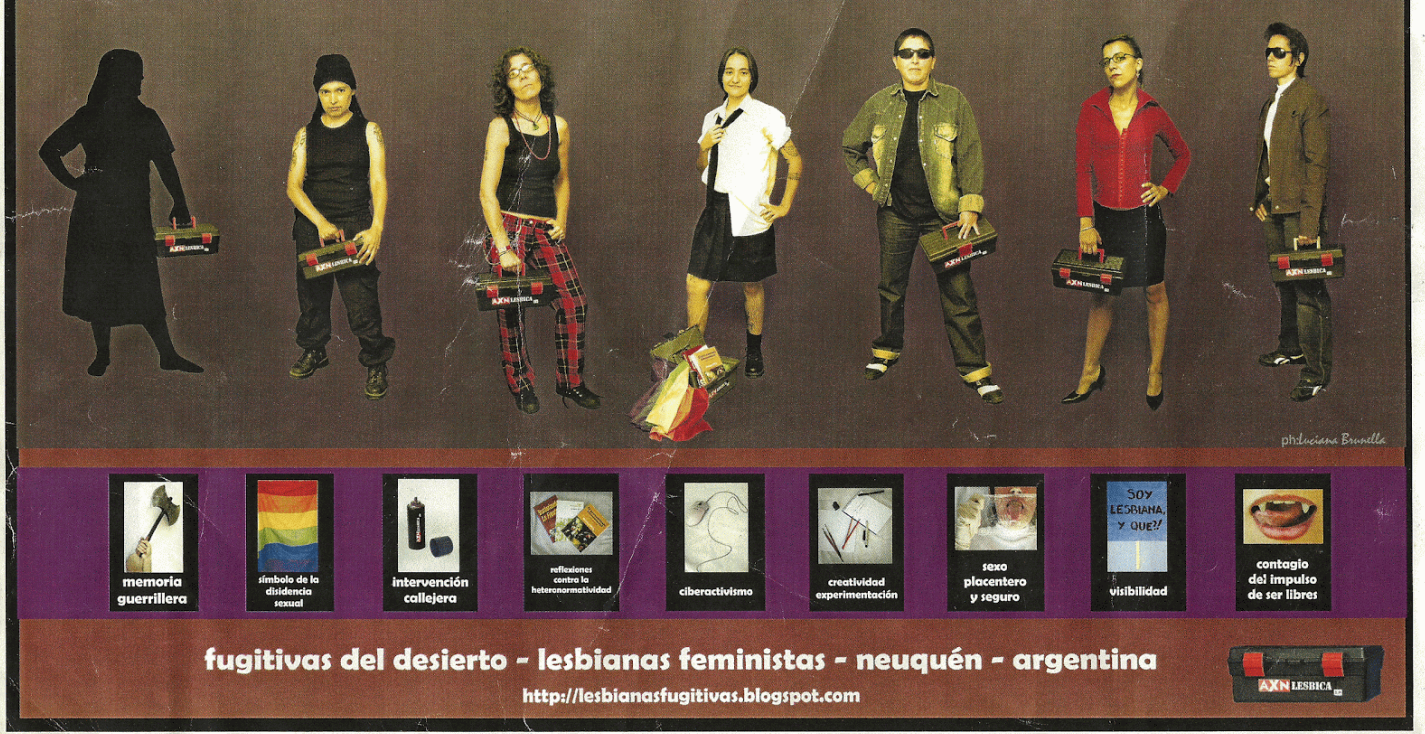

Figura 2. AXN lésbica 1.0 - Kit autoinstalable para boicotear el régimen político de la heterosexualidad, Fugitivas del desierto, 2008. Programa de Memorias Políticas Feministas y Sexogenéricas, CeDInCI UNSAM.

Si bien referimos a esta acción como un afiche, originalmente estaba compuesto por siete escenas, que además de haber formado parte de la imagen general, también se reprodujeron en distintos tamaños y se instalaron en el espacio público por separado. En dicha composición principal se encontraban siete figuras: por un lado, seis representaciones posibles de la identidad lésbica que, a partir de distintos atuendos, poses y accesorios, implicaban diferentes gradientes de masculinidad y feminidad y una séptima figura ensombrecida, aludiendo de forma inclusiva, pero conflictiva a la vez, a la experiencia lésbica aún invisible, que oscila entre el silenciamiento social y una resistencia que la empuja a empuñar una pose activa, decidida, en acción, a pesar de la opacidad a la que se la reduce. Sobre la parte inferior del mismo afiche, se desplegaban diferentes características de la acción lésbica, dispuestas como si fueran herramientas constitutivas de dicho kit: memoria guerrillera, símbolo de la disidencia sexual, 
intervención callejera, reflexiones contra la heterosexualidad, ciberactivismo, creatividad-experimentación, sexo placentero y seguro, visibilidad y finalmente, contagio del impulso de ser libres.

Para sus integrantes, el objetivo de esta acción era no sólo visibilizar las diferentes estéticas lesbianas sino también crear nuevas ficciones del activismo, disponibles para cualquiera que estuviera dispuesta a abrir esa caja de herramientas. Por eso, además de pensar cómo este conjunto de representaciones sobre las identidades lésbicas buscaba empujar los imaginarios somáticos en pleno proceso de normalización de dicha identidad sexual, intersectando diferencias de clase, de raza, corporales y etarias que desarticularon el mentado asimilacionismo de la diferencia lésbica, me interesa llamar la atención sobre cómo este proceso es aludido a través de la apropiación lúdica de los imaginarios heteromasculinizados de la agencia política. Procedimiento que volvieron posible a partir del trabajo con figuras de acción, comúnmente consumidas y coleccionadas por infancias y adolescencias biopolíticamente asignadas al género masculino, en la forma de muñecos, pero también a través de sus representaciones gráficas en formato de figuritas. Algo que era imitado en esta acción a través de la circulación individualizada de estas distintas formas del ser/hacer lésbico. En ese sentido, AXN lésbica no sólo buscaba representar la identidad lesbiana como un devenir prófugo de productivización poética y política desde el cual desmarcarse y hacer explotar las representaciones opresivas que sostienen y reproducen la heterosexualidad obligatoria como un régimen político cultural de producción normada de cuerpos y deseos (Wittig 2006), sino también generar, a partir de esta apropiación torcida de la fantasía heteromasculina, una tensión considerable y creativa al interior de las matrices de imaginación multitudinaria de lo político. Se trata entonces de un tipo de política centrada en la visibilidad y reinvindicación de la identidad lesbiana como un ejercicio crítico de resistencia al borramiento y la invisibilización. A la vez, este ejercicio cuestiona las economías simbólicas que reproducen formas de desigualdad sexogenerizadas en los movimientos sociales que concentran las definiciones prescriptivas de cuándo acontece la acción (política) y quiénes son capaces de llevarla a cabo, fisurando las nociones dominantes de lo político al desprivatizar críticamente las representaciones culturales de la masculinidad.

\section{Juego con lo que quiero}

El conjunto de acciones hasta aquí abordadas nos acercan a modos diferenciales de acción política que diagramaron, en medio de las resonancias sociales de la crisis económica, otros repertorios sensibles para la protesta sexual que de forma lúdica, a través de complejas formas de apropiación de lo infantil, prestaron atención a los modos en que la violencia sobre los cuerpos se concentraba en la articulación entre micro y macropolítica. A continuación, me gustaría detenerme en una acción que dialoga en esta misma línea, pero que introduce un deslizamiento aún más sutil, cuya dirección señala la capacidad de estas agencias poético políticas de producir modos de afirmación colectiva que, además de posicionarse públicamente ante los modos de gestión y control corporal implicados en las asignaciones biopolíticas del género, transforman su reflexión sobre la violencia en una oportunidad sensible para la demanda social de protección para las infancias.

Serigrafistas Queer es una plataforma anómala de reflexión política y producción colectiva de máquinas serigráfícas que al calor de movilizaciones vinculadas a los movimientos feministas y sexodisidentes, ocupan el espacio público 
para poner en circulación una serie de imágenes que apuestan críticamente a desvincularse de la representación temática de los conflictos sociales. Estas imágenes elaboran en su lugar formas sensibles de intervenir de manera transversal en los ordenamientos sexo genéricos normados de la acción política. De esta manera, construyen en la calle laboratorios de exploración subjetiva en los que distribuyen consignas, poesías, denuncias o imágenes alusivas a un conflicto socio sexual en soportes relativos a la vestimenta de quien se acerca a participar de la acción, pero también desde soportes comunicativos propios de las movilizaciones sociales, como banderas, panfletos, volantes o prendedores personales, volviendo los repertorios expresivos de las movilizaciones sociales herramientas de desidentificación e interrupción de los sistemas normados de enunciación e identificación sexo genérica de los cuerpos en acción.

Sus inicios se remontan al año 2007, cuando la artista Mariela Scafati convoca a un taller abierto de serigrafía en el local de la galería Belleza y Felicidad bajo el nombre de Primer Encuentro de Serigrafistas Gay para producir mensajes, carteles y otros dispositivos gráficos para lucir en la Marcha del Orgullo LGTB realizada al día siguiente en Plaza de Mayo. Pero será en el año 2008, luego de su participación en el Festival de Arte Queer organizado por la Federación Argentina de Lesbianas, Gays, Bisexuales y Trans (FALGBT) realizado en el Colegio Nacional de Buenos Aires, un festival especialmente dedicado a la interacción con adolescentes, cuando la propuesta de este no-grupo se transforme, al realizar un desplazamiento político en sus identificaciones y reemplazar en su nombre la palabra gay por queer, permitiendo así un tipo de apertura acorde a sus deseos de articulación múltiple entre distintas trayectorias sexopolíticas.

A partir de ese año, y de forma gradual, comenzarán a materializarse las características que definirán las acciones de Serigrafistas Queer: la producción de un taller abierto de serigrafía para intervenir y ocupar el espacio público usando la técnica para la impresión de imágenes y textos con una alta posibilidad de reproducción y a muy bajo costo, que se convierten, en su contacto con las multitudes organizadas de los movimientos políticos, en herramientas fácilmente apropiables que permiten la incorporación de múltiples actores a la acción, un antecedente que los vincula de forma inmediata con una larga serie de prácticas artísticas críticas de intervención pública que tensionaron su vínculo con la política (Expósito 2011), como por ejemplo el antes mencionado Taller Popular de Serigrafía, del cual Mariela Scafati formó parte originalmente.

En la experiencia de este grupo se puede observar la producción de nuevas formas de acción política que anteriormente señalábamos como constitutivas de este cambio de época, en el marco de los derroteros de la crisis neoliberal que azotó al país en el tránsito de la década de los años noventa y principios de los 2000. Se trata de un modo particular de construcción que prioriza el diseño de plataformas móviles -de allí que hayan adoptado la identificación como un "no grupo"- donde se deja de lado la identidad orgánica de un colectivo para construir una especie de refugio en el tránsito de la acción sobre el presente. Un lugar en el que emergen de forma situada las herramientas para producir intervenciones poético políticas que desestabilizan el orden heteronormado de una sociedad en un intenso flujo de invención creativa en el que los cuerpos y sus deseos se tocan, chocan, friccionan y articulan formas de ensoñación urgentes.

El 28 de Octubre de 2017, en el marco de la 6ta Jornada Lúdico Cultural Comunitaria "Antón Pirulero" organizada por la Escuela Normal Superior n ${ }^{0} 5$ del Barrio de Barracas, espacio dedicado a la creación de juegos participativos callejeros 
para niñes y grandes, motivado como una acción situada en pos de la reflexión y por la defensa de los derechos de niños, niñas y adolescentes en los bordes de la Ciudad de Buenos Aires, Serigrafistas Queer fue invitado a participar y para ello elaboraron la estampa "Soy lo que deseo y juego con lo que quiero". Una consigna afirmativa con tono de rima infantil y escrita a mano que se desplegaba a lo largo del yablón serigráfico junto a una serie de pequeños dibujos con trazos voluntariamente disímiles entre sí que representaban objetos como telescopios, cocinas, varitas mágicas, polleras, espadas, barcos, pelotas de fútbol, zapatos con tacos, labiales, instrumentos musicales y herramientas como rastrillos, palas, destornilladores y martillos, referenciando explícitamente el necesario reconocimiento de culturas materiales lo suficientemente amplias para incluir y validar todos los modos posibles de juego que desean y practican les niñes.

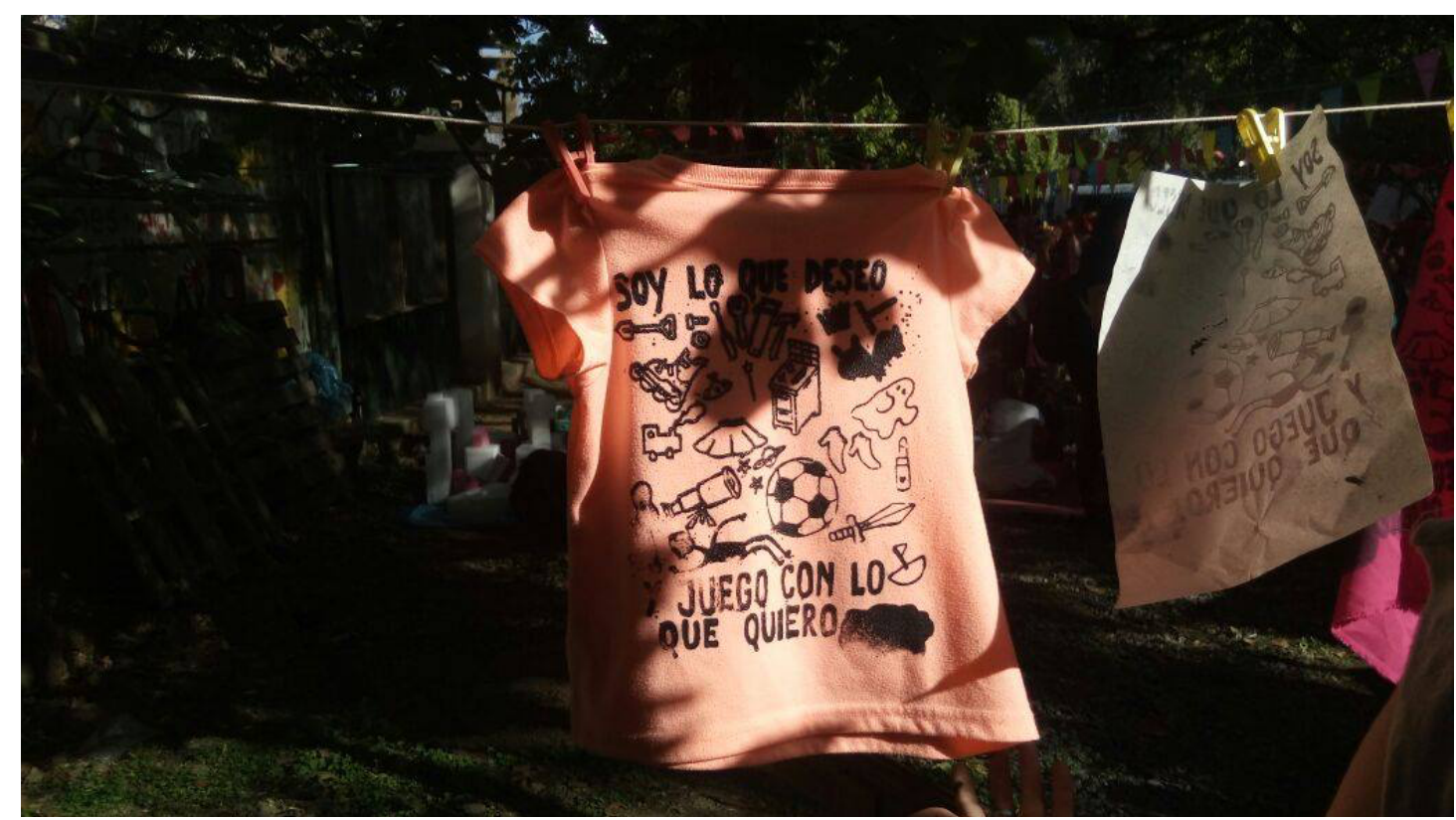

Figura 3. Soy lo que deseo, juego con lo que quiero, Serigrafistas Queer, 2017. Registro de la intervención en la 6ta Jornada Lúdico Cultural Comunitaria "Antón Pirulero" organizada por la Escuela Normal Superior $n^{\circ} 5$ del Barrio de Barracas, Buenos Aires, Argentina. Ask - Archivo de Serigrafistas Kuir.

El proceso de producción de la imagen, tal como muchas otras de las estampas producidas por Serigrafistas Queer, había resultado de una conversación entre sus integrantes en las que debatieron sobre la restricción sexogenerizada de juegos y juguetes, y su distribución forzada por el binomio de imperativos culturales que guionan las experiencias normativas del "ser hombre" y "ser mujer". Para Serigrafistas Queer, la cultura material de los juguetes puede pensarse como "uno de los corsets más tempranos que la sociedad usa para actuar sobre nuestros deseos" como mencionan en su proyecto-personalidad paralela ASK, el Archivo de Serigrafistas Kuir, donde registran a través de fotografías, entrevistas y textos su producción como no-grupo.

Otro aspecto interesante del proceso de socialización de la imagen es que a pesar de que su reproducción estuvo a cargo de les niñes, quienes entre juego y juego se acercaban a la mesa de trabajo instalada en la calle y aprendían el funcionamiento de la técnica serigráfica estampando prendas de ropa que las personas a su alrededor ofrecían para que luego se vistieran con ellas, tal como lo había imaginado Serigrafistas Queer, así mismo muchos adultos presentes pedían que su propia ropa fuera estampada con esta consigna, expresando en voz alta su deseo por reclamar la liberación de lo infantil en sus propias vidas. 
La articulación de otros lenguajes sensibles en torno a la silenciosa violencia que opera a través de la cultura material de la imaginación infantil logró involucrar a les participantes en nuevos modos de imaginar demandas de reparación, contención y cuidado, a la vez que rasguña las fronteras prescriptivas y acríticas que organizan de manera desigual la pertinencia de las emociones como sustratos pre políticos de orden privado, sustrayendo su protagonismo en la organización política de la vida pública y en especial, en las economías de escucha de las demandas deseantes de les niñes. La potencia transformadora del juego, de la inocencia y de la fantasía en este caso, puede pensarse como un proceso colaborativo de politización del cuerpo social e individual en relación a los derechos de las infancias, proponiendo a través de estos artefactos sensibles, modos no sólo de acción en tiempo presente, sino también modos de producción anacrónica de justicia, afecto y alianza sobre les niñes que no pudieron ser o que fueron pero en medio de intensos procesos de violencia.

\section{Una política diagonal}

Sin duda, el trabajo de Kathryn Bond Stockton en The Queer Child, or Growing Sideways in the Twentieth Century (2009), sobre las complejas articulaciones de lo queer en la infancia es un antecedente inevitable para pensar cómo estas formas de politización pública de los imaginarios normativos en torno al sexo a través de lenguajes expresivos socialmente caracterizados como infantiles se pueden inscribir, al mismo tiempo, como un esfuerzo por repolitizar la niñez, pero también como una crítica hacia los modos en que se representa el acontecimiento de lo político.

Si existe un rasgo que caracteriza la aproximación al significado social de la infancia o hacia una definición relativamente estable sobre la niñez, dice la autora, es la opacidad. Ante ello, recupera una premisa desde la cual, en su trabajo, sitúa en un lugar diferencial el protagonismo de la imaginación en las formas de contacto entre lo queer y lo infantil, que se vuelve proporcionalmente relevante para contextualizar las conexiones que hemos descrito con anterioridad en los repertorios sensibles de estos colectivos de activismo artístico: el silencio alrededor de lo queer en la infancia es solo roto a través de la ficción (Stockton 2009). Para Stockton, los procedimientos ficcionales -incluidas las prácticas artísticas-son el espacio donde podemos encontrar mecanismos capaces de ofrecer formas para que algunas infancias queer puedan materializarse, volverse representables o inteligibles.

Partiendo de reconocer que las trayectorias de desarrollo socialmente construidas no se adaptan a los cuerpos y vidas reales de les niñes, Stockton afirma que los procesos acumulados en las transformaciones culturales recientes del modelo capitalista en curso, han vuelto a "los niños" un objeto extraño, incluso perverso, para el estudio y la comprensión de los adultos. Por esa razón, tal como lo indica su título, se esfuerza por dar cuenta de qué manera les niñes expresan su agencia como sujetos a través de formas de crecimiento laterales, que logran desacomodar las expectativas del adultocentrismo, eludiendo los saberes acumulados históricamente sobre la infancia.

La lateralidad que propone la autora es una estrategia que agencian las infancias especialmente ante el imperativo cultural que define su desarrollo: las economías rectas -o bien podríamos decir straight- que condensan la expectativa del buen crecimiento. Un movimiento vertical, hacia arriba, que alude no sólo a la obtención de una estatura y una masa corporal estandarizada bajo parámetros de la normalidad capacitista, sino también, un movimiento que funciona análogamente como un desplazamiento unidireccional, como el efectivo discurrir en una narrativa de guiones rectos, instituidos 
a la fuerza sobre cada cuerpo según el género asignado, la clase social de pertenencia y el color de piel, que marca a seguir para acceder a una buena vida, donde la madurez permite el crecimiento físico e intelectual que demanda el trabajo, donde el trabajo permite la independencia económica que se necesita para abandonar la unidad familiar de origen y construir la propia a través de vínculos heterosexuales con fines reproductivos, que eventualmente cumplirán las mismas expectativas y se acomodarán al mismo ciclo evolutivo que parte y se vuelve efectivo mediante la pérdida paulatina de la infantilidad y las formas de subordinación que a esta experiencia se le asocian.

Lo queer en este sentido, emerge en esos vectores de singularización que abren las diagonales, las demoras, los torcimientos, los anacronismos y las alianzas interespecie al sentido instituido de cómo debe ser un niño, y especialmente, sobre los modos en que su sexualidad, su deseo y su cuerpo tienen que acomodarse a las exigencias de la normalidad heterorreproductiva. En su trabajo, Stockton demuestra e insiste sobre la importancia de las prácticas culturales, dado que estas mismas proponen imágenes, crean afectos y producen experiencias que el poder hegemónico desconoce, para acceder a esas formas laterales de significación, entendimiento y contacto con lo infantil, revelando múltiples formas de queerización de lo infantil e infantilización de lo queer, que de una u otra manera, hacen estallar, a través del empoderamiento que suponen sus sentidos adversos, las construcciones sociales que dominan de forma hegemónica las potencialidades de la infancia.

Como hemos visto hasta ahora, un rasgo constitutivo o transversal de las experiencias de activismos artísticos elaborados por grupos feministas, lésbicos y queer antes mencionados, es el lugar diferencial que proponen para entrar en contacto con lo infantil: ya sea a través de las coreografías corporales de juegos callejeros que yuxtaponen la memoria afectiva de la diversión despreocupada en el espacio público, mientras que señalan retrospectivamente y de manera incómoda no sólo sus efectos performativos como pedagogías sexuales en el pasado, sino también como mecanismos reapropiables para escenificar la perdurabilidad del estigma que subyace en la vida social adulta de esos mismos cuerpos que replican a través del pánico sexual y la lesbofobia estructural, proxemícas discriminatorias, incluso dentro de los feminismos, como observamos en la acción La Mancha Lesbiana de Mujeres Públicas. Esto también puede observarse en la acción de Fugitivas del Desierto, AXN lésbica, donde la expropiación contraproductiva de la agencia infantil, reservada privativamente a través de juguetes heteromasculinizados, exclusivos para los cuerpos asignados biopolíticamente como varones, activa por un lado, gracias a su dimensión lúdica, la posibilidad de jugar, desear y celebrar en tiempo presente la agencia crítica, sexual y transformativa en distintos espectros de masculinidades y feminidades lésbicas, consideradas residuales, falladas, insuficientes o invisibles históricamente, mientras redefine las condiciones instituidas sobre los cuerpos y las sexualidades habilitadas para ser inteligibles como sujetos de un movimiento o protagonistas de modos diferenciales de agencia política. Así mismo se hace presente a través de alianzas intergeneracionales y aproximaciones espectrales como en el caso Serigrafistas Queer en el proceso de impresión serigráfica de su estampa Soy lo que deseo, juego con lo que quiero, donde niñez y adultez elaboran un reclamo colectivo sobre la autonomía corporal y sexual desde una temporalidad queer que cruza de forma contrapuesta dos horizontes de acción: uno entre aquellos que exigen esa libertad como un horizonte para su crecimiento a futuro y aquellos que reclaman de manera retrospectiva esa libertad para volver a comprender, entrar en contacto y melancólicamente ejercer justicia con la censura, la prohibición y el borramiento al que tuvieron que sobrevivir en el pasado.

Como podemos ver, todas estas formas de acceso queer a la politicidad de lo 
infantil comparten como rasgo distintivo una economía afectiva muy específica, que me interesa aquí profundizar. Ya sea a través de rasgos formales asociados a la precariedad de juguetes descartables, o la escenificación de formas de contacto corporal multitudinarias basadas en la alegría, el juego y la diversión, todas estas acciones antes descritas modulan un acceso afirmativo al ejercicio de lo político. Un rasgo que como hemos visto anteriormente, las ha desplazado en su valoración cultural, al no responder a las demandas afectivas, ni temáticas, a las que se han asociado los activismos artísticos mayores en la historia del arte argentino. Detenernos en los repertorios sentimentales asociados a sus culturas materiales o a las coreografías corporales que sus intervenciones performáticas desataron, puede ayudarnos a entender con mayor precisión tanto su reducción selectiva como formas de acción meramente culturales en la disputa política por el presente, pero también puede ofrecernos mejores caracterizaciones de cómo estos modos queer sobre lo infantil (des)hacen la oportunidad de lo político.

\section{De lo menor a lo minoritario}

En el texto Our Aesthetic Categories: Zany, Cute, Interesting, Sianne Ngai (2012) se interesa por los modos en que la experiencia estética ha sido transformada por las condiciones del capitalismo tardío. Para ello, observa un conjunto de mutaciones en el marco de los juicios estéticos de la época y señala que existen al menos tres categorías que pueden dar cuenta, como reflejos sensuales y afectivos, de los modos en los que los sujetos contemporáneos trabajan, intercambian y consumen: la estética mercantil de lo lindo, la estética discursiva de lo interesante y la estética performática de lo payasesco. Para la autora, estas herramientas nos pueden ayudar a comprender algunas de las dinámicas más importantes que subyacen actualmente en la sociedad, a su vez interceptando dimensiones de clase, sexo, género y raza, no sólo porque están señalando procesos económicos, sino también porque nos permiten profundizar en problemas mayores dentro de la teoría estética que continúan caracterizando la elaboración, diseminación y recepción de la cultura en el presente. Estos incluyen: las implicancias en la íntima relación entre la obra de arte autónoma y la forma de la mercancía; la mixtura compleja de afectos tanto negativos como positivos que resultan en la naturaleza ambivalente de muchas de nuestras experiencias estéticas; el estado ambiguo de la vanguardia, que de una manera zombie persiste incluso pese a que su "desaparición o imposibilidad" es destacada como uno de los rasgos constitutivos de la posmodernidad; la relevancia de la estética para los juicios críticos dirigidos a producir conocimiento; el futuro de la noción de arte como juego contrapuesto al trabajo en un mundo donde el trabajo inmaterial está siendo crecientemente estetizado; y la relación "suplementaria" entre el arte y el discurso teórico en sí, todavía más acelerados con el ascenso de una cultura artística hiper institucionalizada, entre muchos otros.

Estas categorías estéticas dentro del repertorio vigente con el que hablamos de manera directa sobre nuestras prácticas cotidianas de producción, circulación y consumo cultural, son interesantes para Ngai a su vez porque implican lo que ella describe como estados de la debilidad o sentimientos menores, no catárticos, es decir que no facilitan la acción, o que no conducen ni culminan en algún tipo de liberación per se, sino que son políticamente ambiguos, muy buenos para diagnosticar estados de agencia suspendida, una condición que arriesga a definir como estructural en el marco de la subjetividad posmoderna. Se trata en su conjunto, entonces, de categorías triviales basadas en sentimientos ambivalentes, o incluso explícitamente contradictorios, juicios 
estéticos que son afectados por economías morales que los caracterizan como fuerzas débiles, de baja intensidad, desafiliadas directamente de las fuerzas concéntricas acumuladas en la noción instituida de belleza, eso que Adorno llama "la esfera de lo intocable", asociada sistémicamente a la expresión de la nobleza, la singularidad, la justicia, la simetría y las proporciones exactas.

El caso particular de lo lindo, una categoría estética suave que emerge de la esfera de la cultura de masas como opuesta al arte de clase alta, es definido por la autora como una actitud sentimental que brota en el encuentro con aquellos objetos diminutos y/o débiles, subordinados y delicados, definidos formalmente por la simpleza, o la ausencia de complejidades técnicas, que en el marco de la sociedad de consumo se asocian con lo infantil, lo femenino, lo inocente y lo hogareño. En ellos cree encontrar una forma de estetización de la impotencia, un sentimiento ambivalente que desarrollamos en nuestra relación con las culturas materiales que fundan nuestra vida íntima, laboral y pública donde tomamos contacto con estas formas que, plantea Ngai, indexan una distancia paradójica entre consumidor y mercancía, distancia que se acorta como efecto de un tipo de empatía abrasiva que desarrollamos ante estos objetos lindos, tiernos e infantiles, que ella considera antropomorfizantes, en tanto reconoce el llamado de protección, cuidado y cariño que estos producen sobre nuestros cuerpos una vez que entramos en contacto con ellos. Se trata de un tipo de experiencia afectiva que, tal como lo mencionamos anteriormente, insiste en su condición feminizada en tanto replica una economía de cuidado sobre objetos que parecieran tener vida propia, pero de manera ambivalente dado que dicha dulzura o vulnerabilidad despierta impulsos irresistibles, hasta compulsivos, de dominio, control y posesión, algo que Daniel Harris denomina "sadismo del consumidor". Un proceso de transmisión afectiva sobre los sujetos donde la ternura logra, por un lado, entablar relaciones de interlocución entre lo vivo y lo inanimado, pero sólo a través de su propio exagerada pasividad, desempoderamiento y vulnerabilización, intentando de manera utópica recuperar la dimensión cualitativa de su uso, pero simultáneamente manipulándonos a sentir lástima por su debilidad, abatimiento por su distancia, e impotencia al no poder poseerlos por completo.

A pesar de que esta categoría es históricamente reconocida por Ngai como una herramienta de análisis relativamente estable surgida en el siglo XIX en Estados Unidos, el rango de objetos que caen sobre este juicio distintivo, comenta la autora, parece haberse expandido durante el siglo XX, extendiéndose de una relación reducida meramente a aquellas "cosas pequeñas", para directamente aludir a personas menores. Un movimiento que ella asocia con una reestructuración histórica donde lo lindo, pero también lo infantil, parece haber cambiado de algo inequívocamente positivo hacia algo negativo, o por lo menos ambiguo, en su productividad social.

En ese sentido, pensar las culturas materiales y las referencias simbólicas asociadas a lo infantil que emergen en el análisis de estas acciones desarrolladas por grupos de activismo artístico como Mujeres Públicas, Fugitivas del Desierto y Serigrafistas queer implica dar cuenta de cómo los juguetes como materialidades precarias, los juegos callejeros como coreografías corporales y los dibujitos como modo de representación inocentes pueden, por un lado, desmontar su productividad como tecnologías de género (De Lauretis 1989) ya instituidas en los procesos de socialización de las infancias, es decir, como máquinas y procedimientos que trabajan por afirmar modos de reconocimiento, cognición y producción de las identificaciones masculino/femenino como tecnologías sociales coercitivas que reglamentan discursos y epistemologías heteropatriarcales en la vida cotidiana, asociando cada sexo con cierto contenido cultural, estableciendo valores y jerarquías desiguales que orientan, restringen y coercionan el crecimiento de les niñes, dando cuenta que el género no es 
una propiedad natural, sino el conjunto de efectos de enderezamiento producidos en los cuerpos, en los comportamientos y en las relaciones que estos establecen en el marco de lo social; y por otro, desmontar la falsa simplicidad que Walter Benjamin reconocía en la relación entre les niñes y los juguetes, para pensarla en su lugar como una poderosa compulsión que busca asimilar la relación sujeto-objeto a través de un poder empático, que comparte el kitsch y el arte popular en otra medida, donde la dimensión fetichizable del objeto es precisamente esta ilusión de personalidad animada que marca un desplazamiento fantasmático capaz de intensificar las relaciones de dominio, control y posesión simbólica de la mercancía sobre quien se afecta anímicamente con ella.

A pesar de que las culturas materiales asociadas a imaginarios infantiles, al movilizar afectos como ternura, inocencia, debilidad y subordinación, son asociadas epistemológicamente con la pérdida de poder, en realidad han demostrado ser capaces de elevar demandas muy profundas, entre ellas la seducción de ser comprados, el deseo por ser tocados o la desesperación por ser parte de su alegría, como si una energía viva los controlara y los volviera irresistibles, volviendo explícita la capacidad que tienen estos sentimientos ingrávidos en la maleabilidad significante del cuerpo. Algo que queda comprobado, en palabras de Ngai, cuando observamos cómo la fuerza de lo lindo, pero también de lo tierno,y todos esos otros sentimientos que aquí vemos conectados con la infancia, actúan la potencia performática de su poder cuando ante ellos se nos vuelve imposible no encoger nuestros cuerpos, afinar nuestras voces, conmovernos por el amor y cuidado que nos despiertan, o como, también menciona Stockton, cuando logran seducirnos a través de la memoria corporal subjetiva que invoca melancólicamente aquella infancia perdida o incluso, aquella que nos fue negada.

Me interesaba recuperar en profundidad estas reflexiones en torno a lo lindo como una categoría estética porque nos puede permitir dar cuenta de cómo y por qué las culturas materiales involucradas en las acciones llevadas adelante por colectivos de activismo artístico como Mujeres Públicas, Fugitivas del Desierto y Serigrafistas Queer vinculadas a imaginarios infantiles han sido consideradas formas minorizadas de acción política, es decir, prescindibles, de bajo impacto, de poca necesidad, secundarias o en muchos casos inoportunas o irrelevantes para las exigencias adultocéntricas de aquello que puede definirse como straight-politik: un canon temporal, afectivo e imaginal que restringe epistemológicamente la inteligibilidad de lo político, reduciendo sus potencias a las demandas que impone la lógica colonial del rendimiento, la efectividad, los objetivos rectos, los intereses prácticos, las acciones concretas, los sentidos coherentes $\mathrm{y}$, especialmente, los resultados transparentes. Una puesta en escena que exige la reproducción acrítica de guiones instituidos sobre la imaginación política que necesita de la serialidad de figuras melodramáticas de estoicismo heteromasculino, la feminización revictimizante de la precariedad y la reproducción obstinada de una esperanza pragmática basada en el pegamento indolente que sostiene la promesa cruel de la heteroreproductibilidad del orden democrático. Un aparato de captura subjetivo que, como hemos podido ver, también retoma lo straight como una orientación prescriptiva, donde la rectitud, la superioridad moral y la seriedad afectiva, contornea extorsivamente la legitimidad de lo históricamente definido como político, reduciendo como meramente cultural (Butler, 2016) aquellas experiencias que por sus sentidos o modos de hacer activan un modo diferencial de agencia en su deseo de transformación de lo real.

En contraposición a la compleja profundidad que caracteriza las estructuras sentimentales en las que se reconocen las tradiciones políticas transformativas, estos afectos de menor intensidad, usualmente descartados por su incapacidad constitutiva de 
portar significados complejos para el diseño de la política por venir, portan en su lugar la promesa de nuevas formas de relacionabilidad entre los sujetos y los objetos. En ese sentido, quisiera proponer que este conjunto de apropiaciones queer de lo infantil, produce un desplazamiento contraproductivo sobre los modos en que dichos imaginarios son desactivados políticamente por el adultocentrismo estructural de la straight-politik convirtiendo la minorización simbólica de sus lenguajes expresivos en una oportunidad para activar devenires minoritarios (Perlongher 1997, Guattari y Rolnik 2006) desde estos mismos. Si bien es cierto que parte de la debilidad que se reconoce en estas imágenes afectivas para el diagrama de una nueva sensibilidad política tiene que ver con su creciente instrumentalización por las lógicas de la identificación mercantil, la ingenuidad de lo lindo y lo tierno, tanto como la condición lúdica de los cuerpos en movimiento, nos ofrece la oportunidad de ponernos en contacto con la realidad a través de experiencias no complejas, liberadas del compromiso moral de la profundidad, de la exigencia del efectismo y del imperativo autosacrificial, reconociendo en su lugar, sus modos diagonales de intervención en la experiencia de transformación de la vida en común. Es a través del poder insospechado de características suaves, personajes infantiles, acciones divertidas, objetos absurdos y pequeñas operaciones humorísticas, que si bien provienen de las esferas de la cultura de masas y de los basureros emocionales que diagraman los regímenes heteropatriarcales que vigilan la definición de lo político, emergen intifadas diminutas, confrontaciones en voz baja y temporalidades raras sobre el presente que de alguna $u$ otra manera abren posibilidades para que lo diferente ocurra.

Estas formas de imaginación queer que se han abierto lugar de manera obstinada en la historia reciente en torno a los cruces siempre conflictivos entre arte y políticas sexuales en el contexto argentino, proponen un tipo experiencia sensible que además del efecto relajante que produce, por su condición lúdica y humorística, nos recuerda repetidamente de nuestra capacidad de organizarnos de forma alegre, al devolvernos la posibilidad de agenciar críticamente experiencias colectivas que expresan preocupación pero al mismo tiempo protegen aquello que nos da placer, una condición estructural en todas las agendas centradas en la liberación del cuerpo y sus deseos. Así es como, entonces, la conflictividad de lo diminuto, lo inmaduro, lo débil o inoportuno, como rasgos constitutivos de lo socialmente definido como infantil, puede hacer que esas imágenes sentimentales, no operativas para la política adulta, ésa que se escribe en mayúsculas, trasciendan las exigencias morales que la determinan y puedan abrir agencias paralelas de politización crítica, movilizando empatía hacia las vidas queer que piden ser cuidadas, demostrándonos capaces de activar formas de reconocimiento de lo vulnerable que funden el compromiso ético por una existencia colectiva digna a partir de la liberación de todas las diferencias, allí donde la rectitud de la historia y la política propone una sociedad ascética de individuos en eterna competencia guionados por la exigencia normalizante de lo único.

\section{Bibliografía citada}

Butler, Judith. 2016. "El marxismo y lo meramente cultural”. En: ¿Reconocimiento o redistribución? Un debate entre marxismo y feminismo, Judith Butler y Nancy Fraser, 67-87. Madrid: Traficantes de Sueños. 
2007. El género en disputa. El feminismo y la subversión de la identidad. Madrid: Paidós.

Cuello, Nicolás. 2014. "Flujos, roces y derrames del activismo artístico en Argentina (2003-2013): Políticas sexuales y comunidades de resistencia sexoafectiva". Errata\#, no 12 Enero-Junio, 70-95.

De Lauretis, Teresa. 1989. Technologies of Gender. Essays on Theory, Film and Fiction. London: Macmillan Press.

Di Filippo, Marilé. 2019. Estéticas políticas. Activismo artístico, movimientos sociales y protestas populares en la Rosario del nuevo milenio. Rosario: UNR Editora.

Expósito, Marcelo. 2011. "Serigrafistas Queer en Plaza de Mayo". Ramonaweb, 7 de noviembre. Disponible en http://www.ramona.org.ar/node/40128 fecha de consulta: 20/10/2017

Flores, val. 2009. "Una poética del desvío. Prácticas minoritarias lésbicas feministas queer". Texto presentado en la mesa "Comunicación y género" de las Jornadas Nacionales de Estudiantes de Comunicación Demoliendo Teles IV "Comunicación, política, subjetividad y poder"-15, 16 y 17 de Octubre de 2009 - Facultad de Derecho y Ciencias Sociales - Universidad Nacional del Comahue.

Fugitivas del Desierto. 2010. "Poéticas de la subjetividad. Nuestros cuerpos como itinerarios del activismo Lésbico-Feminista”. En Cultura y Política, AA.VV. Neuquén: Centro de Estudios Culturales Contemporáneos, Universidad Nacional del Comahue.

González, Malala. 2015. La organización negra. Performances urbanas entre la vanguardia y el espectáculo. Buenos Aires: Interzona.

Guattari, Félix y Rolnik, Suely. 2006. Micropolítica. Cartografías del deseo. Madrid: Traficantes de Sueños.

Lazzarato, Maurizio. 2006. "La forma política de la coordinación”. Brumaria, n 7 , 340-350.

Longoni, Ana y Gustavo Bruzzone, comps. 2008. El Siluetazo. Buenos Aires: Adriana Hildago.

Longoni, Ana. 2012a. "El delirio permanente”. Separata, n 17, Diciembre, 3-20.

— 2012b. "Zona liberada. Una experiencia de activismo artístico en la última dictadura". Boca de Sapo, no 12, 44-50.

—. 2010a. "Fotos y Siluetas: Dos estrategias en la representación de los desaparecidos". En Los desaparecidos en la Argentina. Memorias, representaciones e ideas (1983-2008), comp.: Emilio Crenzel, 35-57. Buenos Aires: Biblos.

—. 2010b. "Tres coyunturas del activismo artístico". Voces en el Fénix, nº1, 90-93. 
- 2009. "Activismo artístico en la última década en Argentina: algunas acciones en torno a la segunda desaparición de Jorge Julio López". Errata \# n 0, 12-35.

—. 2007. "Encrucijadas del arte activista en Argentina". Ramona, no 74, 31-43.

—. 2005. “¿Tucumán sigue ardiendo?”. Sociedad, n 24, 1-11.

Ngai, Sianne. 2012. Our Aesthetic Categories: Zany, Cute, Interesting. Massachusetts: Harvard University Press.

— 2005. Ugly Feelings. Cambridge, Massachusetts: Harvard University Press.

Perez Balbi, Magdalena. 2019. Habitar/Confabular/Crear. Activismo artístico en La Plata. EDULP: La Plata.

Perlongher, Néstor. 1997. Prosa plebeya. Ensayos 1980 - 1992. Buenos Aires: Colihue.

Rosa, María Laura. 2010. «Nos fundó el malestar y nos sostuvo el placer. Mujeres Públicas, ¿Cuestiones privadas?», en: Jornadas (Des)tramando prácticas culturales urbanas desde el género y la sexualidad. Un diálogo entre artistas, investigadores/as y activistas, AA.VV. Buenos Aires: Instituto Interdisciplinario de Estudios de Género (IIEGE), Facultad de Filosofía y Letras, Universidad de Buenos Aires.

Stockton, Kathryn Bond. 2009. The Queer Child, Or Growing Sideways in the Twentieth Century. Durham: Duke University Press.

Wittig, Monique. 2006. El Pensamiento Heterosexual y Otros Ensayos. Madrid: Egales. 